ISSN 0103-9954

\title{
AVALIAÇÃO DA ETAPA DE DERRUBADA E PROCESSAMENTO DE EUCALIPTO PARA CELULOSE
}

\section{EVALUATION OF CUTTING AND PROCESSING OF EUCALYPTUS WOOD FOR PULP}

\author{
Maurem Kayna Lima Alves ${ }^{1} \quad$ Odilon Oliveira Ferreira $^{2}$
}

\section{RESUMO}

Este trabalho teve por objetivo avaliar a etapa de derrubada e processamento de madeira de eucalipto para polpa em uma empresa de celulose e papel. A avaliação abrangeu os seguinte itens: (1) caracterização do aproveitamento do tempo; (2) quantificação das capacidades de produção teórica e efetiva; e (3) determinação dos custos de produção. A metodologia baseou-se no estudo de tempos operacionais e capacidades de produção. Verificou-se que as paradas de ordem técnica são as maiores causas de interrupções do trabalho juntamente com os deslocamentos. Pela natureza, essas interrupções são passíveis de redução, o que resultaria em aumento da capacidade de produção pelo incremento da eficiência operacional. A eficiência operacional alcançou 71,80\%. Os custos com mão-de-obra operacional representaram entre 64,30 e 66,47\% dos custos diretos da operação.

Palavras-chave: Mecanização florestal, colheita de madeira, avaliação de desempenho.

\begin{abstract}
This paper aims to evaluate a cutting and processing of wood for pulp in a pulp and paper manufacturing company. The analysis comprised the following items: (1) characterization of time's utilization; (2) quantifying of the theoretical and effective production capacities; and (3) determination of production costs. The methodology was based in the study of the operational times and capacities of production. The pauses due to technical problems are the gre atest causes of interruptions along with deslocation. According to their nature, these interruptions are supposed to be reduced, and it would reduce the increasing of the production capacity by improvement of
\end{abstract}

1. Eng. Florestal, MSc. em Engenharia Agrícola/CCR/UFSM. Rua Venâncio Aires, 2288/303. 97010-004. Santa Maria. RS.

2. Eng. Florestal, MSc., Prof. Titular do Departamento de Engenharia Rural/CCR/UFSM. 97105900. Santa Maria. RS. 
operational effectiveness. The operational efficiency was $71,80 \%$. The costs in personal to operate the system represented from 64,30 to $66,47 \%$ of the direct costs of operation.

Key words: Forest mechanization, wood harvesting, performance evaluation.

\section{INTRODUÇÃO}

No princípio, as atividades de colheita de madeira baseavam-se em trabalhos manuais e força animal. Com a evolução da mecanização e as mudanças políticas e econômicas, o quadro foi alterando-se em todo o mundo. As evoluções que ocorreram no Brasil, tanto no que se refere às empresas florestais quanto ao que diz respeito a órgãos governamentais e à sociedade são bastante notáveis da década de 70 em diante. Até então, o único critério para exploração de madeira era a viabilidade econômica. Nesta fase foram introduzidas as primeiras motosserras profissionais para corte e os tratores agrícolas modificados para o arraste de toras. Durante aquela década iniciou um processo de melhoria dos equipamentos nacionais existentes e a partir de 1980, foi incorporado ao processo de colheita florestal o conceito de manejo florestal. Paralelamente, iniciou a utilização de tratores derrubadores (feller-buncher) de tesoura hidráulica e de serra, arraste com tratores agrícolas adaptados com pinça, chamados miniskidders, e desgalhamento com grades, cujo objetivo era reduzir o contato do homem com as árvores, diminuindo o risco de acidentes. Na década de 80 nos países Europeus, especialmente na Escandinávia, e nos anos 90 no Brasil, começou a discussão em torno do fator ambiental na utilização econômica de florestas. Simultaneamente, com a redução das taxas de importação e outras facilidades, o Brasil entrou na maior onda de mecanização da colheita de madeira de sua história (MALINOVSKI, 1996).

Um sistema de abastecimento industrial de madeira, como também podem ser chamados os sistemas de colheita de madeira, de acordo com SANT'ANNA JÚNIOR (1992), consta de três atividades ou operações básicas: corte / derrubada; baldeio / arraste e transporte. Estas podem conter sub-operações, como desgalhamento, seccionamento, descasque, e contam com atividades de apoio, como o planejamento, controle operacional e de custos e recursos humanos.

Para a avaliação da eficiência de um sistema de produção há dois parâmetros básicos, que são interdependentes, a serem considerados: produtividade e custos. Entretanto, estes não são os únicos fatores relevantes, principalmente em se tratando de atividades dependentes de recursos naturais renováveis. Os aspectos relacionados à conservação do ambiente e às condições de trabalho do homem são de suma importância.

Segundo STÖHR (1981), o estudo do trabalho ou análise do sistema de trabalho divide-se em análise e síntese, sendo a primeira a pesquisa do desenvolvimento do trabalho sem intervenções na estruturação do mesmo. Já a síntese compreende a pesquisa do desenvolvimento do trabalho previamente estruturado com a finalidade, por exemplo, de aumentar os rendimentos. Para realizar a análise do sistema de trabalho é preciso subdividir o sistema em atividades parciais.

É preciso ressaltar que o enfoque que se pretende dar neste 'estudo do trabalho' não é primordialmente aquele da filosofia Taylorista, segundo a qual o ideal para atingir o objetivo do "the one best way", ou 'a melhor maneira de se fazer algo', é o estudo de tempos e movimentos, para 
padronizar os movimentos e fixar o tempo para executá-los. Essa visão, em termos ergonômicos, é totalmente discutível, segundo FIALHO \& SANTOS (1995). O que se pretende com as colocações deste autor é salientar que o estudo dos tempos proposto para esta pesquisa será baseado numa visão mais global do trabalho e não numa minuciosa fragmentação que, além de não trazer dados úteis para o que se pretende, ainda incorrem numa possibilidade de maior imprecisão na tomada de dados.

Nas companhias florestais da Escandinávia cerca de $50 \%$ das derrubadas eram feitas com motosserras até inícios da década de 80 e atualmente este método representa menos de 5\% do total. Nas operações de desbaste foi mais difícil implantar a mecanização, mas o desenvolvimento de um harvester de pequeno porte, em meados da década de 80, tornou isso possível. Hoje mais de $70 \%$ dos desbastes são completamente mecanizados (WÄSTERLUND, 1994).

No entanto, enquanto não é viável a substituição imediata, ou mesmo a curto prazo, de um sistema manual ou semi-mecanizado por um totalmente mecanizado, não devem ser desprezadas as avaliações e o controle operacional como instrumento para otimização do sistema vigente. Os testes operacionais e a busca do desenvolvimento e aperfeiçoamento de equipamentos e sistemas adaptados à situação de cada empresa são o caminho para atingir níveis crescentes de produtividade, menores custos e qualidade do processo e do produto.

O empenho em otimizar o rendimento de sistemas de produção pouco mecanizados deve ser constante, pois deve-se considerar que há determinadas condições topográficas e/ou edáficas que praticamente impedem a mecanização com os equipamentos atualmente disponíveis. Assim, uma certa parcela da produção provavelmente ainda continuará a ser executada com métodos similares ou derivados dos atualmente empregados por um período de tempo relativamente longo.

O objetivo deste trabalho foi avaliar a etapa inicial do sistema de produção de madeira para polpa empregado pelas prestadoras de serviço de uma empresa de celulose e papel do Estado do Rio Grande do Sul, sem quaisquer intervenções, aplicando e adaptando métodos e conceitos encontrados na literatura. Tal avaliação abrange os seguinte itens:

(1) caracterização do aproveitamento do tempo;

(2) quantificação das capacidades de produção teórica e efetiva; e

(3) determinação dos custos diretos de produção.

\section{MATERIAIS E MÉTODOS}

\section{Descrição do objeto de estudo}

Os povoamentos onde foram feitos os levantamentos eram formados por Eucalyptus saligna com idade entre 7,5 e 8,5 anos, produzindo em média 420,44 st/ha; o relevo era levemente ondulado a ondulado e o período de avaliação estendeu-se de agosto a novembro de 1996. 
$\mathrm{Na}$ empresa onde se realizou o estudo, a produção de madeira para abastecimento da fábrica é totalmente terceirizada e subdividida. Há uma ou mais prestadoras de serviço para cada etapa da produção. Neste trabalho, serão apresentados os resultados referentes às etapas de corte e processamento (desgalhamento e seccionamento).

\section{Coleta de dados}

As etapas de corte e processamento serão discutidas conjuntamente porque as operações são executadas, em cada talhão considerado, por uma mesma prestadora de serviço e as vezes pelas mesmas equipes e máquinas.

Foram acompanhadas as atividades de três prestadoras de serviço: uma no município de Barra do Ribeiro - empresa A no horto Florestal Barba Negra - e duas no município de Butiá empresa B no horto Leão I e empresa C no horto Corrêa da Silva.

Os dados relativos ao aproveitamento de tempo das equipes trabalhando em derrubada e processamento foram coletados em planilhas específicas mediante o acompanhamento diário das operações e realização de cronometragens, sendo que foram anotadas todas as interrupções à operação, relacionando a causa. Foram acompanhadas 29 equipes, sendo 16 na empresa A, 8 na B e 5 na C.

Quanto à produção, o levantamento foi realizado de forma diferente para a derrubada e processamento. Na derrubada, foram acompanhados 139 períodos de 5 a 15 minutos de trabalho sem interrupções, ao longo da jornada, e contadas as árvores derrubadas no intervalo considerado, sendo que não foi realizada a cronometragem dos ciclos operacionais individuais. Já no processamento, foram feitas amostras onde procedeu-se a cubagem, pelo método de Huber (FINGER, 1992), de todos os toretes processados num intervalo de aproximadamente 30 minutos.

As informações necessárias para efetuar-se a estimativa dos custos de produção foram colhidas através de: questionários com os proprietários das prestadoras de serviço; estimativas do consumo de combustível por máquina; planilhas de aproveitamento de tempo; e tomadas de preços em revendas de máquinas.

\section{Características técnicas da operação}

Em todas as empresas (A, B e C) as motosserras utilizadas eram da marca Stihl, modelo 038, tanto para a derrubada como para o processamento (desgalhamento e seccionamento). As equipes eram constituídas por um motosserrista e um ajudante $(1+1)$, que desempenham uma ou outra atividade, conforme a necessidade e instruções do encarregado, sendo que cada equipe primeiro derruba um eito inteiro para depois iniciar o desgalhamento e seccionamento (processamento). $\mathrm{Na}$ empresa B (Butiá) as equipes têm funções definidas, isto é, trabalham ou na derrubada ou no processamento.

Os eitos são constituídos de quatro linhas ou, nos plantios em curva de nível, por uma largura de aproximadamente 13 metros, sendo que é feita uma derrubada cruzada (árvores direcionadas ao centro do eito) para depois ser efetuado o processamento.

Ciência Florestal, v.8, n.1, 1998 
As equipes trabalham em turno único de 8,8 horas diárias ( 8 horas e 48 minutos de jornada teórica), com uma hora de intervalo para o almoço e realizando pausas para descanso, conforme a necessidade, ao longo da jornada de trabalho.

\section{Determinações}

\section{Aproveitamento de tempo}

Foi elaborado um quadro contendo um resumo das informações obtidas no campo onde figuram os tempos de observação, jornadas total, teórica e efetiva, tempo total de interrupções e a classificação de acordo com a natureza da interrupção, em valores absolutos e percentuais do total. A partir desses dados, foram calculados os índices de aproveitamento de tempo (R).

Foram considerados as seguintes definições para as jornadas de trabalho:

- jornada total (Jtot) - período de tempo compreendido entre a saída dos trabalhadores da sede da empresa para o horto e o seu retorno à mesma, descontando-se a parada para almoço;

- jornada teórica de trabalho (Jte) - período de tempo no qual as equipes estão no horto, em operação ou não; não se considera nesta jornada o tempo perdido com chuvas e o almoço;

- jornada efetiva de trabalho (Jef) - tempo em que as equipes estão efetivamente trabalhando.

$\mathrm{R}_{1}$ - representa o quanto da jornada total de trabalho converte-se em jornada teórica; expressa, basicamente, o tempo gasto com a viagem do local de saída, na cidade, até o horto.

$$
\mathrm{R}_{1}(\%)=\frac{\mathrm{Jte}}{\mathrm{Jtot}} . \quad \text { ou: } \quad \mathrm{R}_{1}(\%)=\frac{\text { Tte }}{\text { Hobs }} \cdot 100
$$

$\mathrm{R}_{2}$ - expressa a relação entre a jornada efetiva e a total, representando, além do tempo gasto na viagem até o horto, o tempo consumido nos deslocamentos acampamento - talhão, as paradas por chuvas e todas as interrupções ocorridas ao longo da jornada.

$$
\mathrm{R}_{2}(\%)=\frac{\text { Jef }}{\text { Jtot }} \cdot 100 \quad \text { ou: } \quad \mathrm{R}_{2}(\%)=\frac{\text { Tef }}{\text { Hobs }} \cdot 100
$$

$\mathrm{R}_{3}$ - mostra a relação entre a jornada efetiva e a teórica, expressando o aproveitamento do tempo realmente disponível para o trabalho (eficiência operacional). Este é o mais significativo índice de desempenho operacional e pela análise das suas causas, se desenvolve o processo de otimização de uma determinada atividade ou sistema de trabalho.

$$
\mathrm{R}_{3}(\%)=\frac{\text { Jef }}{\text { Jte }} \cdot 100 \quad \text { ou: } \quad \mathrm{R}_{3}(\%)=\frac{\text { Tef }}{\text { Tte }} \cdot 100
$$




\section{Capacidade de produção}

A capacidade de produção teórica (CPT) refere-se ao volume produzido, em número de árvores, número de toretes, metros esteres ou metros cúbicos por hora, considerando-se um período de tempo efetivamente trabalhado, como se a eficiência operacional fosse de $100 \%$, isto é, sem considerar as interrupções. A capacidade de produção efetiva (CPE) é obtida pela multiplicação do modelo ajustado ou dos valores estimados de capacidade de produção teórica pelo fator de eficiência operacional $\left(\mathrm{R}_{3}\right)$. Tais conceitos de capacidade de produção foram utilizados tomando-se como base os procedimentos adotados por GINGRAS (1989); SANTOS \& MACHADO (1995) e SANTOS et al. (1995).

Na derrubada, o volume em metros esteres foi calculado do mesmo modo como é calculado nas empresas prestadoras de serviço, isto é, utilizando fator de conversão de número de árvores por metro estere, em função das informações de inventário do talhão. A produção diária foi calculada multiplicando a capacidade efetiva $(\mathrm{st} / \mathrm{h})$ pela jornada de trabalho teórica $(\mathrm{h})$.

Quanto ao processamento, os dados obtidos nas amostragens forneceram o volume processado por unidade de tempo, que foi convertido de metros cúbicos para metros esteres.

\section{Custos de produção}

Estimou-se os custos de produção, para cada prestadora de serviço, com base no método adotado por FERREIRA (1980), efetuando-se as adequações necessárias para cada situação. Primeiramente, obteve-se o custo operacional por hora de cada equipamento, composto por custos fixos e variáveis. O custo de produção foi obtido dividindo-se o custo operacional do equipamento $(\mathrm{R} \$ / \mathrm{h})$ pela capacidade de produção verificada (st/h), chegando-se ao valor consumido por unidade de produção $(\mathrm{R} \$ / \mathrm{st})$. Convém ressaltar que os valores obtidos são estimativas que referem-se apenas aos custos diretos.

Todos os componentes dos custos fixos foram calculados em reais por hora de trabalho, considerando-se a jornada total. Para o cálculo dos custos variáveis, o consumo de combustíveis e lubrificantes corresponde às horas efetivas de trabalho e foi informado pelas próprias empresas

\section{Análises estatísticas}

As análises estatísticas foram feitas, basicamente, através da avaliação e/ou comparação de médias, desvios padrão e coeficientes de variação, sendo que a comparação de médias foi feita depois de comprovada a normalidade dos dados pelo Teste de Lilliefors. Utilizou-se, ainda, análise de regressão e foram determinados intervalos de confiança para os valores referentes à capacidade de produção. Os softwares utilizados nos cálculos e análises foram o Excel 5.0 e Plot-It 3.0. 


\section{RESULTADOS E DISCUSSÃO}

\section{Interrupções e aproveitamento do tempo}

A Tabela 1 apresenta o resumo dos principais dados levantados acerca das interrupções ocorridas no tempo disponível para trabalho. O elevado desvio padrão das médias de interrupções segundo as diferentes causas indica grande variação devida ao acaso. Uma forma de obter médias com menor desvio padrão é aumentar o tamanho da amostra, o que no presente caso não seria viável. O mesmo pode ser afirmado em relação ao tempo de interrupções por dia de trabalho, que oscilou entre 43 minutos e 2 horas e 10 minutos, considerando-se os dias em que acompanhou-se a totalidade da jornada de trabalho.

TABELA 1: Distribuição das interrupções por diferentes causas nas operações de derrubada e processamento.

\begin{tabular}{l|r|r}
\hline \multicolumn{1}{c}{ Tipo de interrupção } & (\% sobre total de interrupções) & Desvio padrão \\
\hline Pausas técnicas & 42,94 & 8,41 \\
Interrupções para deslocamentos & 24,63 & 22,95 \\
Interrupções / esperas e demoras & 16,69 & 8,05 \\
Interrupções / motivos pessoais & 6,49 & 3,23 \\
Interrupções / causas diversas & 4,50 & 22,53 \\
Falhas mecânicas & 3,79 & 17,39 \\
Falhas operacionais & 0,96 & 9,52 \\
\hline
\end{tabular}

O tempo total de interrupções representou, em média, 22,39\% da jornada total de trabalho ou tempo total de observação; 26,08\% da jornada teórica ou tempo teórico; e 39,75\% da jornada efetiva ou tempo efetivo de trabalho. Embora a variação dos dados seja grande, de 8,26\% a 49,42\% no segundo caso e de 9,14 a 92,09\% no terceiro, observa-se que o tempo total de interrupções, na maior parte dos dias ou períodos observados representa uma parcela expressiva da jornada de trabalho.

Como a maior parte das interrupções ocorreu por causas que podem ser ditas controláveis, as mesmas poderiam ser reduzidas através de medidas de planejamento e controle operacional. Por exemplo, as interrupções por causas técnicas, que incluem abastecimentos, afiações e regulagens das motosserras, e os deslocamentos para mudança do local de operação não podem ser eliminadas, mas no presente estudo foram muito prolongadas, sendo possível reduzi-las, ajustando procedimentos, treinamento e motivação da mão-de-obra e aumentando a interação do encarregado de campo com as equipes. Entretanto, não se pode deixar de considerar o aspecto da fadiga dos trabalhadores inerente à tarefa de abate e processamento das árvores. Assim, é possível que o aumento no tempo consumido para certas atividades, como o caso das pausas técnicas e mudanças de local de operação, ocorra como uma forma do trabalhador descansar.

As jornadas teórica e efetiva médias foram 6 h 25 min e 4 h 58 min, com um coeficiente de variação de $19,78 \%$ e 19,76 \%, respectivamente, que expressam uma variação média entre os dados, segundo PIMENTEL GOMES (1990). 
Tomando as operações de derrubada e processamento em conjunto, a jornada teórica representou $79,26 \%\left(R_{1}\right)$ e a jornada efetiva $63,05 \%\left(R_{2}\right)$ da jornada total. A eficiência operacional propriamente dita $\left(\mathrm{R}_{3}\right)$, representada pela relação entre a jornada efetiva e a teórica, ficou em $71,80 \%$.

A eficiência operacional de $71,80 \%$ supera o mínimo recomendado na literatura (MACHADO, 1989; MARCON, 1989), embora pudesse ser incrementada, conforme as considerações acerca das interrupções controláveis da operação. Porém, em se tratando de uma operação semi-mecanizada, que exige grande dispêndio de energia por parte do trabalhador, este índice pode ser considerado satisfatório.

\section{Capacidade de produção}

Verificou-se que, em média, foram derrubadas 158,78 árvores por hora de trabalho ininterrupto, isto é, considerando-se uma eficiência operacional de $100 \%$. Ajustando-se os valores para a eficiência operacional verificada $(71,80 \%)$, chega-se a 114,01 árvores por hora. Para a condição média dos talhões onde se efetuou a amostragem, isso equivale 38,59 st/equipe/hora (capacidade de produção efetiva). A produção diária por equipe chegou a aproximadamente 248 metros esteres de madeira não processada, na jornada teórica de trabalho verificada $(6,42$ horas). Vale ressaltar, porém, a grande variabilidade dos dados, expressa por um coeficiente de variação de $31,12 \%$, para o volume produzido por hora (CPE). O intervalo de confiança para a capacidade de produção efetiva, com um $\alpha$ de $5 \%$, é de 36,61 a 40,87 st/hora/equipe.

A produção teórica média na atividade de processamento é $16,50 \mathrm{st} / \mathrm{h} / \mathrm{equipe}$, o que eqüivale a uma produção efetiva (com a mesma eficiência operacional considerada para a atividade de derrubada) de 11,84 st/equipe por hora. Considerando a jornada teórica observada, esses valores representam uma produção diária de 76,01 metros esteres por equipe. Com base na variação observada, o intervalo de confiança para os dados relativos ao processamento fica entre 10,30 e 13,38 st/hora de produção efetiva, $\operatorname{com} \alpha$ de $5 \%$.

\section{Custos de Produção}

Os dados de produção determinados a campo e os custos fixos e variáveis das diferentes atividades permitiram calcular os custos de produção por empresa, sendo os resultados apresentados a seguir.

\section{Empresa A}

Custos fixos $-\mathrm{C}_{\mathrm{F}}=\mathrm{R} \$ 1,17 / \mathrm{h}$

Custos variáveis $-\mathrm{C}_{\mathrm{V}}=\mathrm{R} \$ 7,71 / \mathrm{h}$

Custo operacional - $\mathrm{C}_{\mathrm{O}}=\mathrm{C}_{\mathrm{F}}+\mathrm{C}_{\mathrm{V}}=\mathrm{R} \$ 8,88 / \mathrm{h}$

Para a capacidade de produção observada, os custos do metro estere na derrubada e no processamento são os seguintes: 
Custo de produção derrubada $=\mathrm{R} \$ 0,29 / \mathrm{st}$

Custo de produção processamento $=\mathrm{R} \$ 0,63 / \mathrm{st}$

Custo da madeira pronta para o descasque $=\mathrm{R} \$ 0,92 / \mathrm{st}$

Nesta empresa, 66,20 \% do total dos custos operacionais deve-se aos custos com a mão-deobra operacional (operadores e serventes), enquanto o total de custos fixos (mensalidades, depreciação, seguro e garagem $^{1}$ ) representa $13,20 \%$ do total. Os demais componentes dos custos em ordem decrescente de representatividade são: gastos com lubrificantes, combustíveis, mão-de-obra de manutenção e gerenciamento, e peças de reposição. Isso demonstra a influência do custo da mão-de-obra nos custos de produção, o que é inerente ao grau de mecanização deste sistema de trabalho.

\section{Empresa $B$}

Custos fixos $-\mathrm{C}_{\mathrm{F}}=\mathrm{R} \$ 0,61 / \mathrm{h}$

Custos variáveis $-\mathrm{C}_{\mathrm{V}}=\mathrm{R} \$ 8,05 / \mathrm{h}$

Custo operacional $-\mathrm{C}_{\mathrm{O}}=\mathrm{C}_{\mathrm{F}}+\mathrm{C}_{\mathrm{V}}=\mathrm{R} \$ 8,66 / \mathrm{h}$

Para a capacidade de produção observada, os custos do metro estere na derrubada e no processamento são os seguintes:

Custo de produção derrubada $=\mathrm{R} \$ 0,19 / \mathrm{st}$

Custo de produção processamento $=\mathrm{R} \$ 0,87 / \mathrm{st}$

Custo da madeira pronta para o descasque: $\mathrm{R} \$ 1,06 / \mathrm{st}$

Do total de custos operacionais, 64,30 \% referem-se aos custos com a mão-de-obra de operadores e serventes, enquanto o total de custos fixos representam 7,07\% do total. Os demais itens em ordem decrescente de representatividade são: custos com mão-de-obra gerencial e para manutenção, lubrificantes, combustíveis e peças de reposição.

\section{Empresa $C$}

Custos fixos $-\mathrm{C}_{\mathrm{F}}=\mathrm{R} \$ 0,61 / \mathrm{h}$

Custos variáveis $-\mathrm{C}_{\mathrm{V}}=\mathrm{R} \$ 7,61 / \mathrm{h}$

Custo operacional - $\mathrm{C}_{\mathrm{O}}=\mathrm{C}_{\mathrm{F}}+\mathrm{C}_{\mathrm{V}}=\mathrm{R} \$ 8,22 / \mathrm{h}$

Para a capacidade de produção observada, os custos do metro estere na derrubada e no processamento são os seguintes:

Custo de produção derrubada $=\mathrm{R} \$ 0,21 / \mathrm{st}$

Custo de produção processamento $=\mathrm{R} \$ 0,66 / \mathrm{st}$

\footnotetext{
${ }^{1}$ Este custo refere-se aos gastos com armazenamento das máquinas e oficina-acampamento nos hortos.
} 
Custo da madeira pronta para o descasque: $\mathrm{R} \$ 0,87$ / st

No caso da empresa C, 66,47\% do total dos custos operacionais deve-se aos custos com a mão-de-obra de operadores e serventes e o total de custos fixos representa $7,41 \%$ do total. Os demais itens em ordem decrescente de representatividade são: mão-de-obra gerencial, lubrificantes, combustíveis e peças de reposição.

Para todas as empresas avaliadas, as estimativas de custos apresentadas indicam que os custos variáveis são responsáveis por cerca de $91 \%$ do total dos custos operacionais, sendo que merece destaque o custo com mão-de-obra operacional, pois em todos os casos este item representou entre 60 e $70 \%$ do total dos custos operacionais. A variação observada no percentual dos custos fixos sobre o total quando considerada a empresa $\mathrm{A}$ em relação às empresas $\mathrm{B}$ e $\mathrm{C}$ devese ao fato de que esta era a única que ainda estava amortizando suas máquinas. Outras diferenças observadas entre as empresas são devidas às estruturas física e gerencial para manutenção das máquinas e supervisão do trabalho.

Estas diferenças refletiram-se nos custos de produção, no entanto, como este não depende apenas do custo operacional, mas também da capacidade de produção, a relação não é diretamente proporcional. O custo operacional mais elevado é o da empresa A, porém seu custo de produção é menor que o da empresa $\mathrm{B}$, pois o rendimento na atividade de processamento (que tem mais peso que o custo da derrubada) desta última é menor.

Entretanto, é importante ressaltar que essas diferenças de capacidade de produção, que interferem diretamente no custo por metro estere produzido, são alteradas pelas condições do povoamento onde a empresa trabalha num dado período.

Com relação aos custos com mão-de-obra é interessante destacar que a empresa A gasta $\mathrm{R} \$$ 0,31/h para gerenciar 40 máquinas, enquanto a empresa $B$ gasta $R \$ 0,84 / \mathrm{h}$ para 24 máquinas e a empresa C R \$ 0,69 para 20 máquinas. Embora esse item represente, em média $8,11 \%$ do custo operacional total (variando de 4,17 a 11,78\%), essas discrepâncias indicam que as empresas B e C podem não estar dimensionando adequadamente os recursos humanos em função do número de máquinas, e com isso, o custo de sua mão-de-obra gerencial torna-se mais elevado.

Comparando-se o valor estimado do custo operacional com o utilizado na empresa, percebese enorme diferença. Enquanto a média estimada das três situações foi em torno de $\mathrm{R} \$ 8,60$ / h, a empresa utiliza um custo operacional de $\mathrm{R} \$ 14,00$ / h. Tal variação deve-se ao método de cálculo empregado, ressaltando que os valores aqui apresentados referem-se apenas a custos diretos.

\section{CONCLUSÕES}

A partir dos dados apresentados, analisados e discutidos, concluiu-se que:

- é possível algum aumento da capacidade de produção na etapa de corte e processamento, pelo incremento da eficiência operacional, reduzindo as pausas técnicas e deslocamentos;

Ciência Florestal, v.8, n.1, 1998 
- a eficiência operacional observada nesta etapa da produção é satisfatória, mas a capacidade de produção está próxima ao limite superior possível de ser obtido para este nível de mecanização;

- os custos com mão-de-obra operacional representam entre 64 e $66 \%$ do total dos custos diretos da operação; informação relevante como instrumento para tomadas de decisões e fato inerente ao nível de mecanização utilizado.

\section{REFERÊNCIAS BIBLIOGRÁFICAS}

FERREIRA, Odilon Oliveira. Anotações didáticas da disciplina de Mecanização Florestal (não publicado), Santa Maria : Universidade Federal de Santa Maria, 1980.

FIALHO, F., SANTOS, N. dos. Manual de análise ergonômica no trabalho. 1. ed. Curitiba : Gênesis, 1995. 290 p.

FINGER, César Augusto Guimarães. Fundamentos de Biometria Florestal. 1. ed. Santa Maria: UFSM / CEPEF / FATEC, 1992. 269 p.

GINGRAS, J. F. Feller-buncher performance in adverse stand and terrain conditions. Tech. Rep. For. Eng. Res. Inst. Can. Pont Claire - Quebec : The Institute, n. 89, aug., 1989. 16 p.

MACHADO, Carlos Cardoso. Exploração Florestal. VI Parte. Viçosa : Universidade Federal de Viçosa - Imprensa Universitária, 1989.

MALINOVSKI, Jorge Roberto. Novas tendências em sistemas de colheita de madeira. In: PRIMER SEMINARIO DE ACTUALIZACIÓN EN SISTEMAS DE COSECHA Y TRANSORTE FORESTAL. Eldorado, Misiones, Argentina. Actas... Eldorado: Universidad Nacional de Misiones/ Facultad de Ciencias Forestales, 1996. p. 59-64.

MARCON, Eloi Jacob. A manutenção preventiva de equipamentos e veículos como fator de segurança na disponibilidade operacional. In: VI SEMINÁRIO DE ATUALIZAÇÃO SOBRE SISTEMAS DE EXPLORAÇÃO E TRANSPORTE FLORESTAL. Curitiba. Anais... Curitiba: UFPR / FUPEF, 1989. p. 217-224.

PIMENTEL GOMES, Frederico. Curso de estatística experimental. 13. ed. Piracicaba : Nobel S.A., 1990. 468 p.

SANT'ANNA JÚNIOR, Mário. Tendências atuais e perspectivas futuras dos sistemas de extração florestal. In: VII SEMINÁRIO DE ATUALIZAÇÃ̃O SOBRE SISTEMAS DE EXPLORAÇÃO E TRANSPORTE FlORESTAL. Curitiba. Anais... Curitiba: UFPR / FUPEF, 1992. p.137160.

SANTOS, Sérgio L. Martins, MACHADO, Carlos Cardoso, LEITE, Hélio Garcia. Análise técnicoeconômica da extração de eucalipto em áreas planas com o "forwarder". Revista Árvore. Viçosa, v. 19, n. 3, p. 213-227, 1995. 
SANTOS, Sérgio L. Martins, MACHADO, Carlos Cardoso. Análise técnico-econômica do processamento de madeira de eucalipto em áreas planas, utilizando o processador. Revista Árvore. Viçosa, v. 19, n. 3, p. 346-357, 1995.

STÖHR, G. W. D. Técnicas de estudo do trabalho Florestal. In: BECKER, G. STÖHR, G. W. D., MALINOVSKI, J. R. III Curso de Atualização sobre Sistemas de Exploração e Transporte Florestal. Curitiba : FUPEF, 1981.

WÄSTERLUND, Iwan. Wood harvesting systems in Scandinavia and environmental aspects. VIII Seminário de Atualização sobre Sistemas de Colheita de Madeira e Transporte Florestal. Curitiba : FUPEF, 1994. 